\title{
Biopreservation and Quality Enhancement of Fish Surimi Using Colorant Plant Extracts
}

\author{
Ahmed A. Tayel $\left(D,{ }^{1}\right.$ Amira G. Bahnasy, ${ }^{1}$ Khaled E. Mazrou, ${ }^{2}$ Abdulrahman Alasmari $\left(\mathbb{D},{ }^{3}\right.$ \\ Haddad A. El Rabey $\mathbb{D}^{4,5}$ Shrifa A. Elboghashy, ${ }^{1}$ and Amany M. Diab ${ }^{6}{ }^{6}$ \\ ${ }^{1}$ Department of Fish Processing and Biotechnology, Faculty of Aquatic and Fisheries Sciences, Kafrelsheikh University, \\ Kafr el-Sheikh, Egypt \\ ${ }^{2}$ Department of Plant Biotechnology, Genetic Engineering and Biotechnology Research Institute, \\ University of Sadat City, Sadat, Egypt \\ ${ }^{3}$ Department of Biology, Faculty of Sciences, University of Tabuk, Tabuk, Saudi Arabia \\ ${ }^{4}$ Department of Molecular Bology, Genetic Engineering and Biotechnology Research Institute, \\ University of Sadat City, Sadat, Egypt \\ ${ }^{5}$ Department of Biochemistry, Faculty of Sciences, University of Tabuk, Tabuk, Saudi Arabia \\ ${ }^{6}$ Department of Aquaculture, Faculty of Aquatic and Fisheries Sciences, Kafrelsheikh University, Kafr el-Sheikh, Egypt
}

Correspondence should be addressed to Ahmed A. Tayel; tayel_ahmad@yahoo.com

Received 27 November 2020; Revised 10 January 2021; Accepted 12 January 2021; Published 30 January 2021

Academic Editor: Fabio Napolitano

Copyright (c) 2021 Ahmed A. Tayel et al. This is an open access article distributed under the Creative Commons Attribution License, which permits unrestricted use, distribution, and reproduction in any medium, provided the original work is properly cited.

\begin{abstract}
The biopreservation, flavoring, and coloration of foodstuffs, e.g., seafoods, with natural plant derivatives are major demands for consumers and overseers. Different colored plant parts, i.e., Hibiscus sabdariffa calyces, Curcuma longa rhizomes, and Rhus coriaria fruits, were extracted and evaluated as biopreservatives, antimicrobial and colorant agents for fish surimi from Oreochromis niloticus. All colorant plant extracts (CPEs) exhibited strong antibacterial activities against screened pathogens, Escherichia coli, Salmonella typhimurium, Staphylococcus aureus, and Pseudomonas aeruginosa. H. sabdariffa extract (HCE) was the most effectual antimicrobial CPEs. S. aureus was the most sensitive strain to CPEs, whereas S. typhimurium and P. aeruginosa were the most resistant strains. The exterior coloration of tilapia surimi with CPEs resulted in great bacterial count reduction in colored products; stored CPEs-colored surimi had enhanced sensorial attributes. HCE-exposed S. aureus indicated bacterial cell lyses in time-dependent manner. CPEs application as colorants and antibacterial and quality enhancing agents is recommended for seafoods' biopreservation.
\end{abstract}

\section{Introduction}

Fisheries products, e.g., whole fish and seafoods, are extremely susceptible to biological decomposition due to their perishable nature and nutritional composition $[1,2]$. The microbial spoilage/contamination is the leading cause from the diverse occurred deterioration types, in stored fish products, which accompanied with severe quality reduction $[3,4]$. Seafood spoilage, with food-borne bacteria, could dangerously influence the shelf-life of the products and could be a threatening risk factor for food-borne diseases transmission, via pathogens' contamination, e.g., E. coli, Salmonella sp., Shigella sp., Staphylococcus sp., Listeria sp., and Clostridium sp. [1,5].

Man continuously depended on plant kingdom to supply him with most of his needs to attain healthier life, higher nutritional beliefs [6]. Natural plant derivatives, e.g., extracts, essential oils, powders, or bioactive compounds, were continually applied effectively for biopreserving of foodstuffs, maintaining their sensorial and microbiological qualities and extending their shelf lives $[4,7]$. 
The lessening of antimicrobial agents' usage, especially in food and health disciplines, was always regarded as the inspiring challenge for overseers and researchers $[8,9]$; the exploration of safe, effectual, and environmentally-innocent alternatives, from biological sources, was always endorsed for application in food preservation and decontamination. Plant-derived antimicrobial compounds were efficaciously employed to preserve numerous foodstuffs, but their usage in seafoods' preservation had, somewhat, a limited success [10-12].

Natural food-grade pigments/colorants were increasingly utilized in food sectors as safe substitutes to synthetic counterparts; this was mostly due to the assumed side-effects and environmental impacts from the chemical-based food colorants and the rising consumers' awareness about that $[13,14]$; they demand fully natural food/beverages that are free from any synthetic substances.

Many types of food colorants were approved, including carotenoids, chlorophylls, anthocyanins, and betalains, for safe applications in food processing; besides to their sensory enhancing attributes, it was evidenced that consumption of naturally-colored foodstuffs was interrelated with increasing immunity and cutback of hazardous diseases, e.g., diabetes, obesity, and cancer $[14,15]$.

It could be more beneficial to apply plant derivatives to achieve many bioactive advantages, e.g., coloration, antioxidation, antimicrobial, quality enhancement, and health promotion $[6,8,11,12]$.

Accordingly, current research was designed for evaluating some colored plant extracts as food colorants, antimicrobial, and biopreservatives for fish surimi toward the enhancement of microbiological and sensorial features of the product.

\section{Materials and Methods}

2.1. Plant Extraction. Diverse plant parts were employed for obtaining their crude extracts, i.e., extracts of Hibiscus sabdariffa calyces (HCE), Curcuma longa rhizomes (CRE), and Rhus coriaria fruits (RFE); plant materials were obtained from El-Kaptin Herbal Company, Egypt. Dried herbal parts, using hot air $\left(45^{\circ} \mathrm{C}\right)$, were powdered to 70 mesh particles size. $200 \mathrm{~g}$ from each ground material were immersed into $1 \mathrm{~L}$ of aqueous ethanol solution (70\%), stirred for $8 \mathrm{~h}$ at 220 $\mathrm{xg}$, and then filtered using filter paper (Whatman no. 2). Vacuum evaporation $\left(40^{\circ} \mathrm{C}\right)$ was applied for omitting $\sim 90 \%$ of extraction solvent, followed by placing in desiccator to almost complete dryness. Extracts, after weighing, were dissolved in distilled water (to have concentration of $10 \%, \mathrm{w} /$ v) and then sterilized using syringe filter (Millipore, $0.22 \mu \mathrm{m})$.

2.2. Microbial Strains. Four standard microbial strains were used in the experiments, Escherichia coli (ATCC 25922), Salmonella typhimurium (ATCC 14028), Staphylococcus aureus (ATCC 25923), and Pseudomonas aeruginosa (ATCC 27853). The bacterial cultures were propagated and screened in Trypticase soy agar (TSA) and Trypticase soy broth (TSB) media (Difco, Sparks, MD).

2.3. Evaluation of In Vitro Antibacterial Capability. The potential antibacterial capabilities of color plant extracts (CPEs), against examined bacteria, were screened, qualitatively, using agar/disc diffusion and quantitatively through appraising of minimal concentrations of bactericidal activity (MBC). Screened bacterial cultures, after refreshment in TSB for $18 \mathrm{~h}$, were centrifuged for harvesting and washed twice with phosphate buffered solution (PBS, $\mathrm{pH} 7$ ). The number of each culture cells was adjusted to $\sim 2 \times 10^{7} \mathrm{CFU}$ (colony forming units)/ml, using PBS for dilution. Cell suspension portions $(100 \mu \mathrm{L})$ were spread onto TSA, to assess disc diffusion, and then discs of filter paper (Whatman No. 41, $6 \mathrm{~mm}$ diameter), impregnated with $25 \mu \mathrm{L}$ from each CPE, were placed to contact the surface of inoculated agar. After incubation of inoculated plates, at $37 \pm 1^{\circ} \mathrm{C}$ for one day, the ZOI (diameter of clear zones from grown bacteria) were precisely measured, in triplicates, and the means of them were calculated.

The MBCs of each CPE were assessed via the method of broth microdilution [9]; using a tissue culture microplate (24-well), bacterial cultures were exposed to gradual CPEs concentrations in TSB. After incubation, as mentioned above, $100 \mu \mathrm{L}$ from each trial were spread, onto TSA plates, incubated, and examined for grown colonies' appearance. $\mathrm{MBC}$ was designated as the least CPEs concentration that caused complete bacterial inhibition, after these steps.

2.4. Application of Colored Extracts onto Fish Surimi. Fish fillets from Oreochromis niloticus (Nile tilapia), weighed 100-120 g each, were offered from the Fish Processing Plant, Kafrelsheikh University, Egypt. Minced fillets were utilized for preparing fish surimi gel [16]. The inoculation of surimi gels, with bacterial cultures, was conducted through blending of individual cultures with raw products to obtain a final count of $\sim 15 \times 10^{5} \mathrm{CFU} / \mathrm{g}$. The inoculated, and control, surimi samples were treated by immersion in the individual CPEs, at concentrations of $2.5 \mathrm{mg} / \mathrm{ml}$ from each [17]. Produced colored samples were then packaged aseptically into polyethylene bags and stored at $4^{\circ} \mathrm{C}$ for one day before subjecting to microbiological and sensorial attributes evaluation.

2.5. Microbiological Examination. Treated fish surimi samples were microbiologically examined to assess the plant colorants' effectiveness in reducing bacterial counts. Samples $(10 \mathrm{~g})$ were aseptically taken from the surface of surimi fingers ( $2 \mathrm{~mm}$ thickness) and from the middle inner parts of fingers, homogenized in buffered peptone water, and subjected to microbial examination. Different microbiological analyses standards were followed to judge the usefulness of 
colorant extracts' treatment, on the elimination of bacterial growth in fish products, as follows:

Escherichia coli enumeration ( $\beta$-glucuronidase-positive) (ISO 16649-2:2001)

Detection of Salmonella spp. (ISO 6579: 2002)

Staphylococcus aureus enumeration (ISO 6888-1:1999)

Detection and enumeration of Pseudomonas aeruginosa (ISO 16266:2006)

2.6. Sensory Attributes Evaluation. A trained team of panelists (14 members, 5 males and 9 females) at Kafrelsheikh University, experienced in seafood evaluation, accomplished the sensory evaluation of CPE-colored fish surimi attributes, i.e., odor, appearance, color, and overall quality, after cold storage $\left(4^{\circ} \mathrm{C}\right)$ for 7 days. The used hedonic scale, for evaluation, ranged from excellent (5) to extremely bad (1) [18].

2.7. Electron Microscopic Imaging. For illustrating potential morphological variations in bacterial cells, after exposure to $H$. sabdariffa calyces extract, for 0,6 , and $12 \mathrm{~h}$, grown $S$. aureus cells ( $18 \mathrm{~h}$ old) were exposed to concentration of $2.5 \mathrm{mg} / \mathrm{ml}$ from extract and microscopically photographed using electron scanning microscope (SEM; Hitachi S-500, Tokyo, Japan) according to Marrie and Costerton (1984). The electron microscopic captures were taken at $20 \mathrm{kV}$ and $20,000 \mathrm{X}$, based on the morphological alterations in treated cells after exposure.

2.8. Statistical Analysis. The triplicated trials' means and standard deviations were computed using Excel sheets software 2013, Microsoft office ${ }^{\mathrm{TM}}$; the significance of variance analysis between individual groups was predicted using the statistical software (MedCalc-V. 11.6.1) with CI of $\geq 95 \%$.

\section{Result and Discussion}

Various colored plant extract (CPE) parts were assessed as potential antibacterial agents against screened food-borne pathogens (Table 1). Generally, the entire CPEs exhibited significantly stronger antibacterial activities against screened pathogens, as evidenced from the clear ZOIs (Figure 1) and the recorded MBCs. The bacterial inhibition potentialities, from CPEs, varied toward examined microorganisms; H. sabdariffa calyces extract (HCE) could be relatively specified as the most significant powerful examined CPE. The subsequent relatively powerful CPE was $R$. coriaria fruits extract (RFE) and then the extract of $C$. longa rhizomes (CRE).

Conversely, $S$. aureus was the most sensitive strain to HCE and both $S$. typhimurium and $P$. aeruginosa were significantly more resistant against this extract. S. typhimurium had the highest recorded resistance toward $\mathrm{CRE}$ and $P$. aeruginosa was the most sensitive against the same extract (Table 1).
Natural food colorants were anciently applied worldwide to increase consumers' ability to diverse foodstuffs. Moreover, these applications of food colorants were recurrently stated to enhance food shelf life and nutritional and therapeutic outcomes due to their potential antimicrobial, antioxidant, anti-inflammatory, and health protection characteristics $[2,19]$. Therefore, the current trials aimed to apply natural colored plant extracts as quality enhancers and antimicrobial biopreservatives in processed fish products. The used concentration from CPEs was $2.5 \mathrm{mg} / \mathrm{ml}$, which was higher than the recorded MBCs from each colorant extract; this was because of the fish products content from protein, lipids, and other food constituents. The components of food, e.g., water, fat, protein, and salt, could increase microbial resistance to microbicides; higher levels from spices or other antimicrobial agents are required to inhibit microbial growth in food systems than when culture media are used $[4,6,20]$. Additionally, the biopreservatives concentrations, to exert the desirable antimicrobial action, were suggested to be higher when examining food products than to study them in vitro, although that if they coupled with further agents, they may support the efficacy to control bacterial pathogens in foods $[21,22]$.

Tilapia fish surimi were supplemented with the extracted CPEs, i.e., HCE, RFE, and CRE, at CPE concentrations of $2.5 \mathrm{mg} / \mathrm{ml}$. The impact of product supplementation with CPEs, on the survival of inoculated food-borne bacterial pathogens, is illustrated in Table 2 .

The microbial counts in control (uncolored) group tended to increase during storage, for all screened strains; the counts in surface parts exceeded those in inner samples for all microbes. The contrary was evidenced in CPEs-colored products, where the bacterial counts in product surface samples were much less than the recorded counts from the inner parts. The treatment impact was very remarkable in the count of S. aureus, in the surface of HCE-colored surimi, and then in P. aeruginosa, in the surface of RFE-colored samples.

The impacts of fish surimi coloration, with CPEs, on the sensorial attributes of products, are indicated in Figure 2. All treatments significantly increased the sensorial characteristics of colored surimi, compared to the control, after cold storage at $4^{\circ} \mathrm{C}$ for 7 days; the coloration with CRE was the most favorable, from panelist team, to enhance the color, appearance, and overall quality.

RFE was the best to improve odor characters of colored products, but it was less effective than the other CPEs for the rest of the examined attributes. Generally, the color and appearance of CPE-colored tilapia surimi were notably improved as indicated by panelists' preferences (Figure 3).

The variations in antibacterial activity, from CPEs toward examined microorganisms, could be explained by the diverse bioactive compounds in each CPE that could have different antibacterial actions against each microbe $[6,12]$. All of the screened plants, herein, were traditionally accustomed for human usage; this guarantees their biosafety and applicability in various food sectors/applications. $R$. coriaria (sumac) is frequently utilized in the 
TABLE 1: Antibacterial activity of plant extracts against food-borne pathogens, measured as the diameter of inhibition zones (ZOI, mm) and minimal bactericidal concentration $(\mathrm{MBC}, \mathrm{mg} / \mathrm{ml})^{*}$.

\begin{tabular}{|c|c|c|c|c|c|c|c|c|c|}
\hline \multirow[t]{2}{*}{ Extracted plants } & \multirow[t]{2}{*}{ Part } & \multicolumn{2}{|c|}{$\begin{array}{l}\text { Salmonella } \\
\text { typhimurium }\end{array}$} & \multicolumn{2}{|c|}{$\begin{array}{c}\text { Staphylococcus } \\
\text { aureus }\end{array}$} & \multicolumn{2}{|c|}{ E. coli } & \multicolumn{2}{|c|}{$\begin{array}{c}\text { Pseudomonas } \\
\text { aeruginosa }\end{array}$} \\
\hline & & ZOI & $\mathrm{MBC}$ & ZOI & $\mathrm{MBC}$ & ZOI & $\mathrm{MBC}$ & ZOI & MBC \\
\hline Hibiscus sabdariffa & Calyces & $19.7 \pm 0.9^{\mathrm{a} 1}$ & 1.6 & $24.5 \pm 1.2^{\mathrm{a} 2}$ & 1.0 & $22.6 \pm 1.2^{\mathrm{a} 2}$ & 1.2 & $20.2 \pm 0.8^{\mathrm{a} l}$ & 1.6 \\
\hline Curcuma longa & Rhizomes & $16.8 \pm 0.8^{\mathrm{b} 1}$ & 2.2 & $18.4 \pm 0.8^{\mathrm{b} 1}$ & 1.8 & $18.2 \pm 0.7^{\mathrm{b} 1}$ & 1.8 & $22.4 \pm 1.2^{\mathrm{a} 2}$ & 1.2 \\
\hline Rhus coriaria & Fruits & $19.3 \pm 1.1^{\mathrm{a} 1}$ & 2.0 & $21.3 \pm 1.2^{\mathrm{c} 12}$ & 1.4 & $23.4 \pm 1.3^{\mathrm{a} 2}$ & 1.2 & $17.1 \pm 0.7^{\mathrm{b} 3}$ & 2.0 \\
\hline
\end{tabular}

${ }^{*}$ Dissimilar superscript letters within a column or superscript numbers within a row indicate difference significance at $\mathrm{CI}=95 \%$.
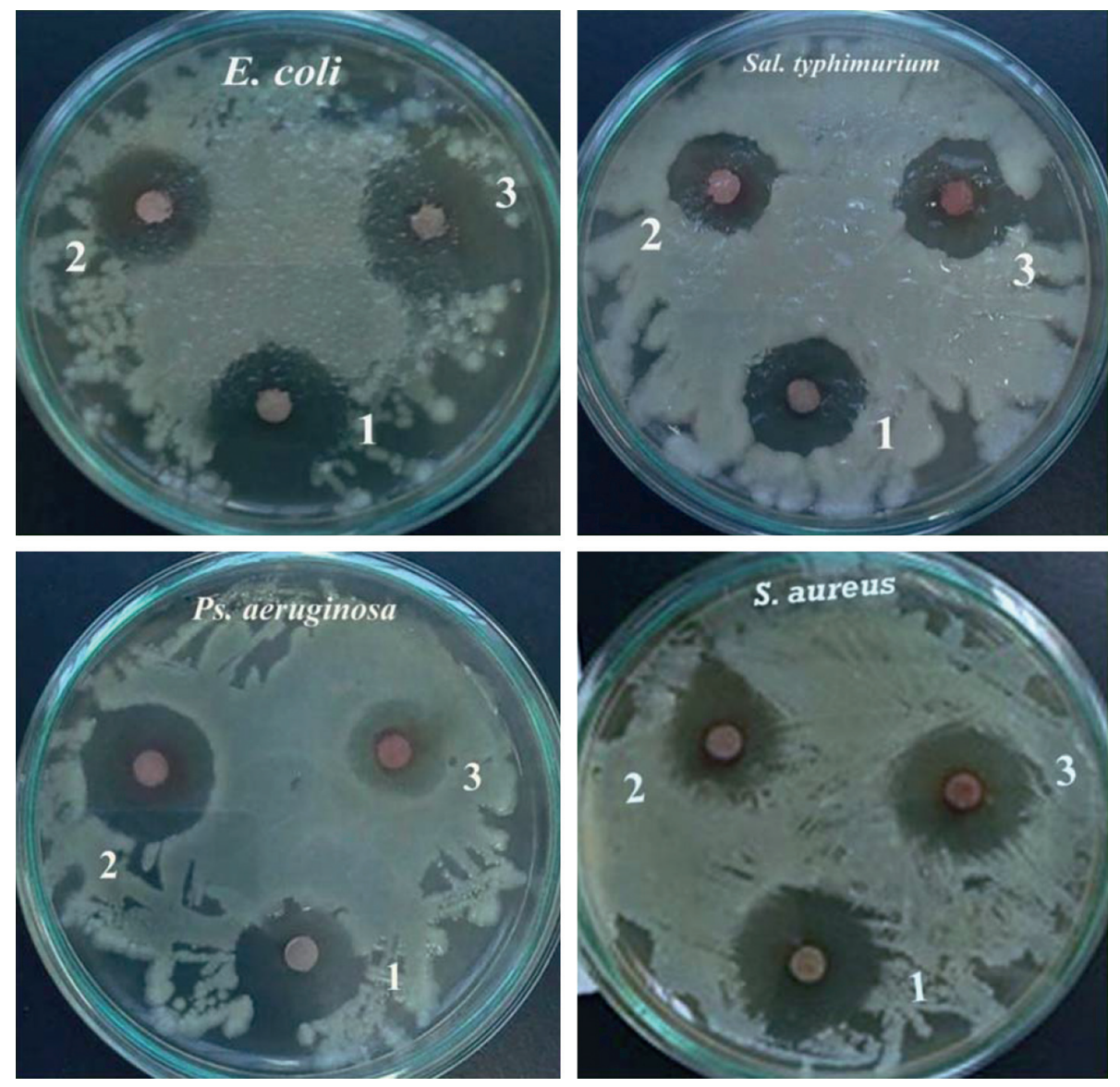

FiguRe 1: Appeared growth inhibition zones after challenging food-borne bacteria with colored extract of Hibiscus sabdariffa calyces (1), Curcuma longa rhizomes, (2) and Rhus coriaria fruits (3), using disc diffusion assay.

TABLE 2: Effect of fish surimi coloration with plant extracts, at their MICs*, on the count of food-borne pathogens in the surface (S) and inner (I) parts, after $24 \mathrm{~h}$ of treatment and storage at $4^{\circ} \mathrm{C}$.

\begin{tabular}{|c|c|c|c|c|c|}
\hline \multirow{2}{*}{ Colorant plant extract } & \multirow{2}{*}{ Examined part in product } & \multicolumn{4}{|c|}{ Food-borne pathogens } \\
\hline & & Salmonella typhimurium & Staphylococcus aureus & E. coli & Pseudomonas aeruginosa \\
\hline \multirow{2}{*}{ Control } & $S$ & $4.3 \times 10^{7}$ & $7.2 \times 10^{6}$ & $7.6 \times 10^{7}$ & $2.2 \times 10^{7}$ \\
\hline & I & $5.8 \times 10^{6}$ & $3.4 \times 10^{6}$ & $2.3 \times 10^{7}$ & $7.7 \times 10^{6}$ \\
\hline \multirow[b]{2}{*}{ Hibiscus sabdariffa } & $S$ & $5.2 \times 10^{3}$ & $1.8 \times 10^{2}$ & $6.1 \times 10^{2}$ & $7.3 \times 10^{3}$ \\
\hline & $\mathrm{I}$ & $7.9 \times 10^{4}$ & $3.2 \times 10^{3}$ & $4.8 \times 10^{3}$ & $5.6 \times 10^{4}$ \\
\hline \multirow{2}{*}{ Curcuma longa } & $S$ & $5.4 \times 10^{4}$ & $7.8 \times 10^{3}$ & $5.7 \times 10^{3}$ & $5.1 \times 10^{2}$ \\
\hline & I & $2.3 \times 10^{5}$ & $8.1 \times 10^{4}$ & $7.2 \times 10^{4}$ & $2.8 \times 10^{4}$ \\
\hline \multirow{2}{*}{ Rhus coriaria } & $\mathrm{S}$ & $7.5 \times 10^{3}$ & $4.4 \times 10^{3}$ & $6.3 \times 10^{2}$ & $2.2 \times 10^{4}$ \\
\hline & I & $6.2 \times 10^{4}$ & $4.9 \times 10^{4}$ & $1.9 \times 10^{4}$ & $7.5 \times 10^{4}$ \\
\hline
\end{tabular}

Plant extract was applied at a concentration of $2.5 \mathrm{mg} / \mathrm{ml}$. Initial microbial addition was $\sim 4 \times 10^{5} \mathrm{CFU} / \mathrm{g}$. 


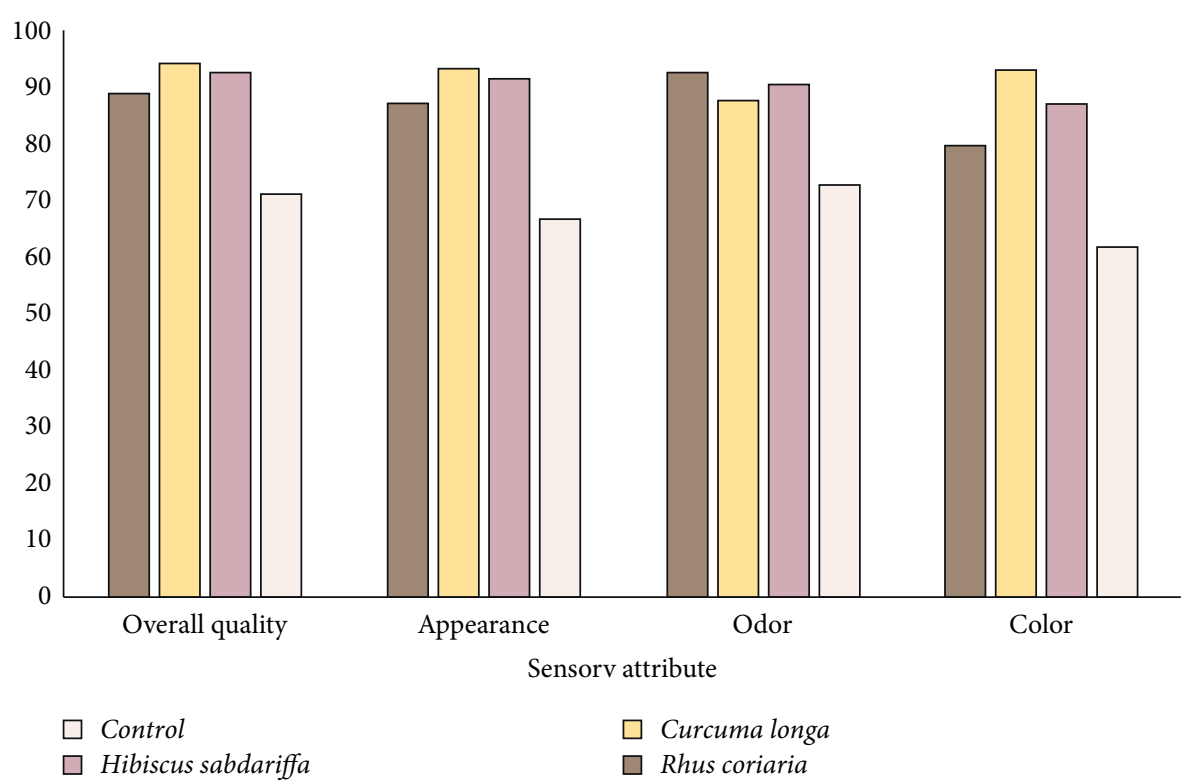

FIGURE 2: Effect of fish surimi coloration with plant extracts on the sensorial attributes of products after 7 days of treatment and storage at $4^{\circ} \mathrm{C}$ Results are means of 14 panelists' scores. Plant extract was applied at concentration of $2.5 \mathrm{mg} / \mathrm{ml}$.

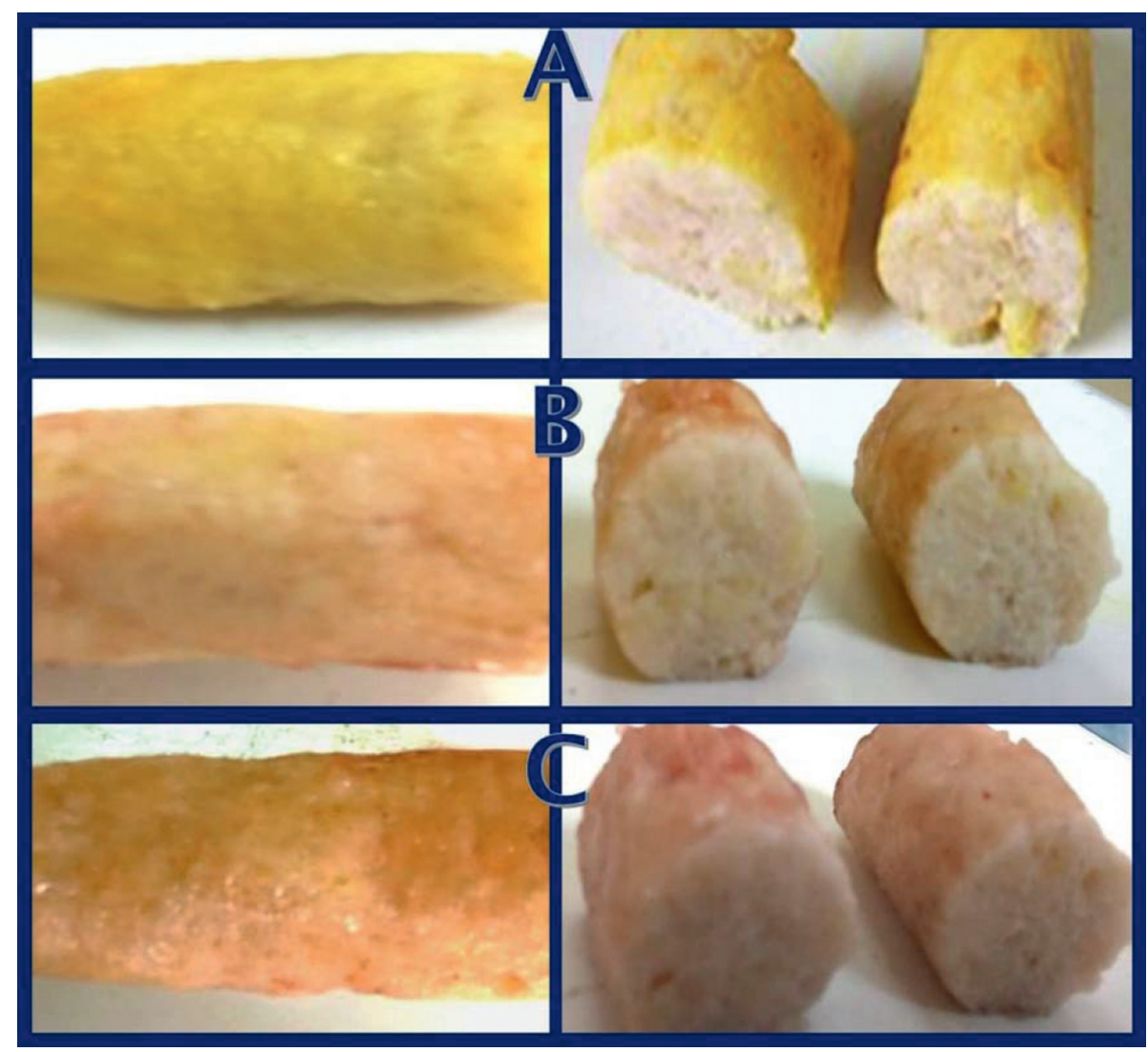

FIGURE 3: Appearance and visual attributes of colored tilapia fish surimi with extracts of Curcuma longa rhizomes (a), Rhus coriaria fruits, (b) and Hibiscus sabdariffa calyces (c), after 7 days of storage at $4^{\circ} \mathrm{C}$. 
Mediterranean area as spice, particularly in seafood and meat dishes. The antimicrobial potentiality from sumac was believed to be generated from its bioactive compounds contents [23]; over 120 aromatic constituents were identified in sumac varieties using chromatography and spectroscopy, most of them belonged to terpenoids and aliphatic compounds [24]. Some studies were published about specific antimicrobial substances in $R$. coriaria, which indicated the presence of 3 potentially antibacterial compounds, i.e., 4methoxy-3,5-di-hydroxy-benzoic acid, gallic acid and methyl ester of 3,4,5-tri-hydroxy-benzoic acid (methyl gallate), in the methanolic extract of $R$. glabra L. These compounds could also represent the responsible bioactive substances in $R$. coriaria, as they belong to the same genus and family $[23,25,26]$.

Turmeric (C. longa) extract also contains many groups from bioactive substances, e.g., alkaloids, glycosides, flavonoids, tannins, and carbohydrates; numerous reports displayed that flavonoids and alkaloids are from most bioeffective compounds, as antimicrobials, in plant kingdom [27]. The entire fractions of C. longa extract were highly effectual against numerous isolates of pathogenic bacteria and the inhibitory effects especially increased in ethanol and hexane extracts of turmeric [28, 29]. As evidenced from microscopically examined bacterial pathogens, exposed microbes to $C$. longa extract appeared with deforming morphology, cell disruption, and lyses of cytoplasmic membrane; this suggested the broad antimicrobial spectrum of the extract and recommended its usage for microbial infections management $[22,27]$.

The main detected bioactive compounds in C. longa extract were reported as curcumin or diferuloylmethane (1,7-bis(4-hydroxy-3-methoxyphenyl)-1,6-heptadiene3,5-dione) oleoresin, curcuminoids, and essential oils $[30,31]$. The powerful antimicrobial of curcumin and C. longa extract, was proved against several types from viruses, bacteria, fungi, and parasites; their biocidal effects were reported to increase through synergism with ordinary antimicrobial agents; many attempts were also conducted to enhance biochemical attributes of curcumin [32-35].

The roselle ( $H$. sabdariffa) calyx was traditionally applied in herbal medicine as herbal drinks, beverages, and flavoring agents in food processing. Most research and clinical investigations revealed that $H$. sabdariffa extract had potent antioxidant, antibacterial, antihypertensive, hepato- and nephro-protective, diuretic/renal effect, and anticholesterol and antidiabetic effects $[36,37]$. These effects were suggested to associate with $H$. sabdariffa strong antioxidant activities, suppression of angiotensin-conversion enzymes (ACE), suppression of $\alpha$-amylase and $\alpha$-glucosidase, and vaso-relaxant effect. Also, other phytochemical compounds, in $H$. sabdariffa extract, such as organic acids (hibiscus acid and hydroxy-citric acid), phenolic acids (protocatechuic acid), and anthocyanins (cyanidin-3-sambubioside and delphinidin-3-sambubioside) were contributed in these therapeutic effects of the extract [36].

The methanolic/aqueous extract of $H$. sabdariffa proved to have in vitro inhibitory potentialities against numerous bacterial species [38]; this biocidal activity was persistent through heat treatment, the alcoholic extract was stronger than aqueous extract, which recommended the application of these extracts for bio-prevention from food contaminants $[37,39]$. The coloring potentialities and antimicrobial and antioxidant activities of used CPEs, especially $H$. sabdariffa extract, could improve the sensorial quality and consumers' ability to the produced fish surimi [40].

The impact of HCE exposure, on the cells morphology, viability, and features of $S$. aureus, is verified from Figure 4. The captured SEM micrographs of zero time-treated (control) $S$. aureus demonstrated that most cells had a natural, smooth, and unified structure (Figure 4(a)). Following the exposure to HCE, for $6 \mathrm{~h}$, remarkable vigorous effects were observed on the bacterial cells morphology (Figure 4(b)); most exposed cells had lyses signs and their inner contents were released, the residual semiintact cells were enlarged and notable lyses initiation was seen. By the exposure period completion, to HCE (after $12 \mathrm{~h}$ ), all exposed bacteria had completely ruptured and lysed; only the cell wall residues and liberated interior cellular contents were detected in this stage (Figure 4(c)).

The bacterial pathogen, S. aureus, was chosen for SEM examination after exposure to $H$. sabdariffa extract because it was the most sensitive strain toward examined CPEs, and H. sabdariffa extract was the most effectual to inhibit this pathogen. This is expected to provide some clear mode(s) of action from the application of CPEs toward bacterial pathogens.

The SEM micrographs of $S$. aureus, exposed to $H$. sabdariffa extract, could demonstrate that many potentially bioactive substance(s), in the extract, may possess some kinds of metabolic interference with microbial proliferation, development, or functioning. The extract could, also, be suggested to possess time-dependent biocidal potentiality, as evidenced from the vigorous alteration/damage in treated cells' morphology that increased with the prolongation of exposure period. The supposed antimicrobial mode(s) of action of $H$. sabdariffa extract, from SEM micrographs (Figure 4), could be through the destruction/lyses of bacterial cell membranes, cytoplasm coagulation, alteration in proteins of cytoplasmic 


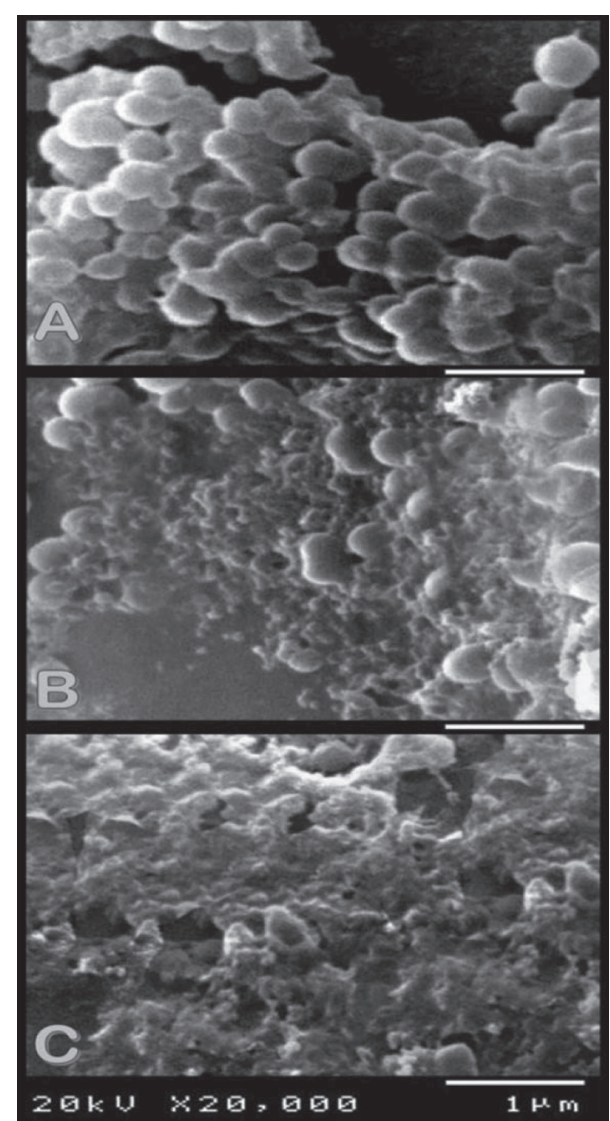

FIGURE 4: Scanning micrographs of treated Staphylococcus aureus with Hibiscus sabdariffa calyces extract after exposure for $0 \mathrm{~h}$ (a), $6 \mathrm{~h}(\mathrm{~b})$, and $12 \mathrm{~h}(\mathrm{c})$.

membrane, seepage of cell contents, interaction with protein synthesis enzymes, or reducing the motive force of protons $[17,36,41]$.

\section{Conclusion}

The colored extracts of screened plants (i.e., H. sabdariffa calyces, $R$. coriaria fruits, and $C$. longa rhizomes) were effectual for inhibiting food-borne bacterial pathogens and augmenting the sensorial attributes of tilapia fish surimi; $H$. sabdariffa extract was the most effectual antimicrobial and C. longa extract was the most favorable colorant. The application of CPEs as colorants and antibacterial and quality enhancing agents could be strongly recommended as powerful alternatives to synthetic and chemical agents for the preservation of tilapia fish surimi.

\section{Data Availability}

The data used to support the findings of this study are available from the corresponding author upon request.

\section{Conflicts of Interest}

The authors declare no conflicts of interest.

\section{References}

[1] L. Gram and P. Dalgaard, "Fish spoilage bacteria - problems and solutions," Current Opinion in Biotechnology, vol. 13, no. 3, pp. 262-266, 2002.

[2] R. C. 2, C. N. Horita, and A. S. Sant'Ana, "Natural products with preservative properties for enhancing the microbiological safety and extending the shelf-life of seafood," Food Research International, vol. 127, Article ID 108762, 2020.

[3] L. Gram and H. H. Huss, "Microbiological spoilage of fish and fish products," International Journal of Food Microbiology, vol. 33, no. 1, pp. 121-137, 1996.

[4] O. O. Olatunde and S. Benjakul, "Natural preservatives for extending the shelf-life of seafood: a revisit," Comprehensive Reviews in Food Science and Food Safety, vol. 17, no. 6, pp. 1595-1612, 2018.

[5] S. Dehghani, S. V. Hosseini, and J. M. Regenstein, "Edible films and coatings in seafood preservation: a review," Food Chemistry, vol. 240, pp. 505-513, 2018.

[6] M. M. Cowan, "Plant products as antimicrobial agents," Clinical Microbiology Reviews, vol. 12, no. 4, pp. 564-582, 1999.

[7] M. R. Corbo, A. Bevilacqua, D. Campaniello, D. D’Amato, B. Speranza, and M. Sinigaglia, "Prolonging microbial shelf life of foods through the use of natural compounds and nonthermal approaches - a review," International Journal of Food Science \& Technology, vol. 44, no. 2, pp. 223-241, 2009.

[8] A. Lopez-Malo, E. Palou, and S. M. Alzamora, "Naturally occurring compounds - plant sources," in Antimicrobials in Food, P. M. Davidson, J. N. Sofos, and A. L. Branen, Eds., pp. 429-451, CRC Press, New York, 2005.

[9] A. A. Tayel, W. F. El-Tras, S. H. Moussa, and S. M. El-Sabbagh, "Surface decontamination and quality enhancement in meat steaks using plant extracts as natural biopreservatives," Foodborne Pathogens and Disease, vol. 9, no. 8, pp. 755-761, 2012.

[10] E. Ernst, "The efficacy of herbal medicine - an overview," Fundamental and Clinical Pharmacology, vol. 19, no. 4, pp. 405-409, 2005.

[11] A. A. Tayel, O. A. Abdel-Monem, S. H. Moussa, and A. I. AlTurki, "Plant extracts as antimicrobials: prospects in food safety and health protection,", in Plant Extracts: Role in Agriculture, Health Effects and Medical Applications, A. Giordano and A. Costs, Eds., p. 311, Nova Science Publishers, Hauppauge, NY, 2013.

[12] N. Gokoglu, "Novel natural food preservatives and applications in seafood preservation: a review," Journal of The Science of Food and Agriculture, vol. 99, no. 5, pp. 2068-2077, 2019.

[13] M. Carocho, M. F. Barreiro, P. Morales, and I. C. F. R. Ferreira, "Adding molecules to food, pros and cons: a review on synthetic and natural food additives," Comprehensive Reviews in Food Science and Food Safety, vol. 13, no. 4, pp. 377-399, 2014.

[14] R. Cortez, D. A. Luna-Vital, D. Margulis, and E. Gonzalez de Mejia, "Natural pigments: stabilization methods of anthocyanins for food applications," Comprehensive Reviews in Food Science and Food Safety, vol. 16, no. 1, pp. 180-198, 2017.

[15] E. B. Rodriguez, M. L. P. Vidallon, D. J. R. Mendoza, and C. T. Reyes, "Health-promoting bioactivities of betalains from red dragon fruit (Hylocereus polyrhizus(Weber) Britton and Rose) peels as affected by carbohydrate encapsulation," Journal of The Science of Food and Agriculture, vol. 96, no. 14, pp. 4679-4689, 2016. 
[16] M. A. Amiza and W. C. Kang, "Effect of chitosan on gelling properties, lipid oxidation, and microbial load of surimi gel made from African catfish (Clarias gariepinus)," International Food Research Journal, vol. 20, no. 4, pp. 1585-1594, 2013.

[17] A. A. Tayel, N. A. Almabady, N. M. Sorour, and A. M. Diab, "Application of natural plant extracts as colorants, preservatives and anti-listerial agents in processed fish products," Journal of Food Safety, vol. 38, pp. 1-7, 2018.

[18] A. A. Tayel, "Microbial chitosan as a biopreservative for fish sausages," International Journal of Biological Macromolecules, vol. 93, pp. 41-46, 2016.

[19] F. Delgado-Vargas and O. Paredes-López, Natural Colorants for Food and Nutraceutical Uses, CRC Press LLC, Boca Raton, FL, 2003.

[20] L. A. Shelef, "Antimicrobial effect of spices," Journal of Food Safety, vol. 6.

[21] S. M. Nasar-abbas, A. K. Halkman, and M. I. Al-Haq, "Inhibition of some foodborne bacteria by alcohol extract of sumac (Rhus coriaria L.)," Journal of Food Safety, vol. 24, no. 4, pp. 257-267, 2004.

[22] M. P. Nguyen, "Synergistic effect of turmeric (Curcuma longa), galanga (Alpinia galanga) powder and lemongrass (Cymbopogon citratus) essential oil as natural preservative in chilled storage of white hard clam (Meretrix lyrata). Orient," Journal of Chemistry, vol. 36, no. 1, pp. 195-200, 2020.

[23] S. Mahdavi, B. Hesami, and Y. Sharafi, "Antimicrobial and antioxidant activities of Iranian sumac (Rhus coriaria L.) fruit ethanolic extract," Journal of Applied Microbiology and Biochemistry, vol. 2, no. 2, pp. 1-5, 2018.

[24] S. M. Nasar-Abbas and A. K. Halkman, "Antimicrobial effect of water extract of sumac (Rhus coriaria L.) on the growth of some food borne bacteria including pathogens," International Journal of Food Microbiology, vol. 97, no. 1, pp. 63-69, 2004.

[25] G. Saxena, A. R. Mccutcheon, S. Farmer, G. H. N. Towers, and R. E. W. Hancock, "Antimicrobial constituents of Rhus glabra," Journal of Ethnopharmacology, vol. 42, no. 2, pp. 95-99, 1994.

[26] H. Tohma, A. Altay, E. Köksal, A. C. Gören, and İ. Gülçin, "Measurement of anticancer, antidiabetic and anticholinergic properties of sumac (Rhus coriaria): analysis of its phenolic compounds by LC-MS/MS," Journal of Food Measurement and Characterization, vol. 13, no. 2, pp. 1607-1619, 2019.

[27] A. Gupta, S. Mahajan, and R. Sharma, "Evaluation of antimicrobial activity of Curcuma longa rhizome extract against Staphylococcus aureus," Biotechnology Reports, vol. 6, pp. 51-55, 2015.

[28] P. S. Negi, G. K. Jayaprakasha, L. Sakariah, and K. K. Sarariah, "Antibacterial activity of turmeric oil: a byproduct from curcumin manufacture," Journal of Agricultural and Food Chemistry, vol. 47, no. 10, pp. 4297-4300, 1999.

[29] M. S. Arshad, Z. Amjad, M. Yasin et al., "Quality and stability evaluation of chicken meat treated with gamma irradiation and turmeric powder," International Journal of Food Properties, vol. 22, no. 1, pp. 154-172, 2019.

[30] E.-K. Song, H. Cho, J.-S. Kim et al., "Diarylheptanoids with free radical scavenging and hepatoprotective activity in vitro from Curcuma longa," Planta Medica, vol. 67, no. 9, pp. 876-877, 2001.

[31] Z. Y. Hosea, L. Kator, and E. H. Rhoda, "Phytochemical properties and antimicrobial activities of aqueous extract of Curcuma longa (Turmeric) rhizome extract," Asian Journal of Research in Crop Science, vol. 2, no. 1, pp. 1-8, 2018.
[32] C. A. C. Ara'ujo and L. L. Leon, "Biological activities of Curcuma longa L," Memorias do Instituto Oswaldo Cruz, vol. 96, no. 5, pp. 723-728, 2001.

[33] R. Singh, R. Chandra, M. Bose, and P. M. Luthra, "Antibacterial activity of Curcuma longa rhizome extract on pathogenic bacteria," Current Science, vol. 83, pp. 737-740, 2002.

[34] R. K. Maheshwari, A. K. Singh, J. Gaddipati, and R. C. Srimal, "Multiple biological activities of curcumin: a short review," Life Sciences, vol. 78, no. 18, pp. 2081-2087, 2006.

[35] I. Shlar, S. Droby, and V. Rodov, "Modes of antibacterial action of curcumin under dark and light conditions: a toxicoproteomics approach," Journal of Proteomics, vol. 160, no. 8, pp. 8-20, 2017.

[36] I. Da-Costa-Rocha, B. Bonnlaender, H. Sievers, I. Pischel, and M. Heinrich, "Hibiscus sabdariffa L. - a phytochemical and pharmacological review," Food Chemistry, vol. 165, pp. 424443, 2014.

[37] G. Riaz and R. Chopra, "A review on phytochemistry and therapeutic uses of Hibiscus sabdariffa L," Biomedicine \& Pharmacotherapy, vol. 102, pp. 575-586, 2018.

[38] M. T. Olaleye, "Cytotoxicity and antibacterial activity of Methanolic extract of Hibiscus sabdariffa," Journal of Medicinal Plants Research, vol. 1, no. 1, pp. 9-13, 2007.

[39] C.-Y. Chao and M.-C. Yin, "Antibacterial effects of roselle calyx extracts and protocatechuic acid in ground beef and apple juice," Foodborne Pathogens and Disease, vol. 6, no. 2, pp. 201-206, 2009.

[40] I. Jabeur, E. Pereira, L. Barros et al., "Hibiscus sabdariffa L. as a source of nutrients, bioactive compounds and colouring agents," Food Research International, vol. 100, pp. 717-723, 2017.

[41] M. Panaitescu and E. Lengyel, "Monitoring the antibacterial activity of Hibiscus sabdariffa extracts," Management of Sustainable Development, vol. 9, no. 1, pp. 31-34, 2017. 